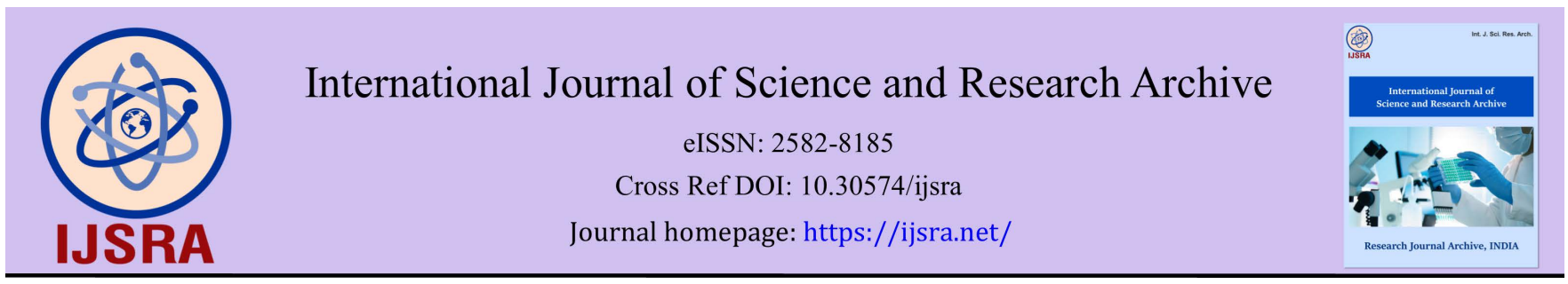

(CASE REPORT)

Check for updates

\title{
Medical expulsive therapy symptomatic aggravation in blind right orthotopic ureterocoele and contralateral impacted left ureteral meatus stones: A Case Report
}

\author{
Abubakar Sadiq Muhammad 1, 2, ${ }^{*}$, Haruna Usman Kamba ${ }^{2}$, Abubakar Isyaku ${ }^{2}$ and Abdullahi Khalid ${ }^{2}$ \\ ${ }^{1}$ IMAN Hospital Runjin Sambo, Sokoto, Nigeria. \\ ${ }_{2}^{2}$ Institute of Urology and Nephrology, Usmanu Danfodiyo University/ Teaching Hospital Sokoto, Nigeria.
}

International Journal of Science and Research Archive, 2021, 03(02), 183-187

Publication history: Received on 12 September 2021; revised on 15 October 2021; accepted on 17 October 2021

Article DOI: https://doi.org/10.30574/ijsra.2021.3.2.0163

\begin{abstract}
A ureterocoele with stone may present with recurrent flank pain and urinary tract infection. Medical expulsive therapy (MET) may be associated with symptomatic aggravation when there is ureteric obstruction or stone impaction. The definitive treatment is by deroofing and retrieval of the stone endoscopically or by open intravesical approach. We report a case of symptomatic aggravation of right orthotopic blind ureterocoele stone and contralateral impacted left ureteral meatus stone following MET using tamsulosin who was treated by open deroofing and retrieval of stones.

Case presentation: This is a 17-year-old lady who presented with recurrent suprapubic colicky abdominal pain that was aggravated by Medical Expulsive Therapy (MET) using tamsulosin but improves with opioid analgesics. Abdominopelvic ultrasound done before MET revealed bladder stone but the repeat ultrasound after the MET revealed bilateral ureterocoele with stones. A computerized tomographic scan urogram (CTU) revealed a right ureterocoele stone and bladder stone. She had bladder exploration with the finding of blind right orthotopic ureterocoele containing stone measuring $2.5 \mathrm{~cm} \times 3 \mathrm{~cm}$ and an impacted peeping left ureteric meatus stone of $1.2 \times 1 \mathrm{~cm}$. She had deroofing of the right ureterocoele and retrieval of the stones bilaterally. The stitches and stents were removed and discharged on 9 and 10 postoperative days respectively. The postoperative period was uneventful.
\end{abstract}

Conclusion: Medical expulsive therapy may be associated with symptomatic aggravation in blind orthotopic ureterocoele and sizeable impacted ureteral meatus stone. Findings of the Imaging studies may be conflicting and inaccurate. Deroofing of the ureterocoele and stone retrieval is associated with a good outcome.

Keywords: Deroofing; Stone; Retrieval; Impaction; Ureterocoele; Aggravation; Tamsulosin; Medical expulsive therapy

\section{Introduction}

A ureterocoele is the cystic dilatation of the intravesical part of the ureter [1]. The incidence of ureterocoele in the newborn ranges from $1 / 500$ at autopsy to $1 / 4000$ in a clinical setting [2]. It is described as a disease of Caucasians because of its rarity in Africans and Asians [3]. It is bilateral in $10 \%$ of the cases [4]. It is 4-7 times more common in females than males [4]. It may be associated with a single or duplex system. In the duplex system it is associated with upper moiety ureter in $80 \%$ of the cases [5]. Single system ureterocoele is more common in female adults [3]. Stone formation occurs in a single system in 4-39\% of the cases [6]. Multiple stones can form in a single system with up to 265 calculi reported [6]. Bilateral stone formation is very rare with less than 15 cases reported in the literature [7]. Embryologically, ureterocoele is due to incomplete dissolution of Chwalla membrane at the uretero-trigonal junction leading to obstruction, dilatation and ureterocoele formation [8]. It can be classified in relation to the renal unit as a single system or duplex system ureterocoele and in relation to the location and configuration of the ureteral orifice, as

\footnotetext{
*Corresponding author: Abubakar Sadiq Muhammad; E-mail: asmgusau@gmail.com

IMAN Hospital Runjin Sambo, Sokoto, Nigeria.

Copyright (@ 2021 Author(s) retain the copyright of this article. This article is published under the terms of the Creative Commons Attribution Liscense 4.0.
} 
intravesical (orthotopic) or extravesical (ectopic) [1]. Stephen [9] subclassifies the orifice into cecoureterocoele, stenotic, sphincteric, sphinctero-stenotic, blind and obstructed. The predispositions for stone formation are ureteral atony, obstruction, urinary stasis, recurrent infection, and history of stone $[10,11]$. This is a rare anomaly that may present with recurrent flank pain and urinary tract infection. The pain may be due to obstruction, stone formation, or infection [12]. The diagnosis can be by ultrasound, intravenous or computerized tomographic scan urogram (CTU) [13]. Renal scintigraphy is also important in the assessment of split renal function and scarring [1]. Medical expulsive therapy is effective for ureteric stones less than $8 \mathrm{~mm}$. In the presence of obstruction or impaction, there may be symptomatic aggravation with MET. Ureterocoele may be treated endoscopically or by an open method. Endoscopic smiling incision or deroofing and cystolithotripsy or percutaneous retrieval of the stone can be done if the stone is big [1,6,11]. Transurethral endoscopic retrieval of the stone can be done after the ureterocoele incision if the stone is small [7]. Open deroofing or marsupialization and retrieval of the stones can be done in low resource settings where the endoscopic facility is not available [3,11]. Symptomatic aggravation following MET in blind ureterocoele stone and impacted contralateral ureteral meatus stone has not been reported in our environment [6].

This paper aims to report a case of symptomatic aggravation of blind right orthotopic ureterocele stone with contralateral impacted left ureteral meatus stone treated by open deroofing and stone retrieval.

\section{Case presentation}

This is a 17-year-old lady who presented with recurrent severe suprapubic colicky abdominal pain for 7 months which was relieved initially by Non-Steroidal Anti-inflammatory Drugs (NSAIDS) but the recent episode of the pain was only improved by opioid analgesics. The physical examination was unremarkable. The initial abdominopelvic ultrasound finding was suggestive of bladder stone and suspicious of ureteral meatus stone (figure 1A) as result of which MET was commenced. The abdominal ultrasound was repeated due to aggravation of symptoms which necessitated withdrawal of tamsulosin and commencement of opioid analgesics and antibiotics leading to relieve of symptoms. The repeat ultrasound was suggestive of bilateral ureterocele with stones (figure 1B). Computerized tomography urogram revealed a right ureterocele stone and a bladder stone (figure 2). Urine microscopy yielded no microbial growth. Full blood count, urinalysis, fasting blood sugar, electrolyte urea and creatinine were within normal limits. She had bladder exploration with the finding of impacted left ureteral meatus stone measuring $1.2 \mathrm{x} 1 \mathrm{~cm}$ and right single system orthotopic blind ureterocele with a stone size of $2.5 \times 3.0 \mathrm{~cm}$ (figure 3 ). She had deroofing of right ureterocele with piecemeal retrieval of the stone fragments, left ureteral meato-lithotomy and bilateral ureteral stenting. She had removal of stitches with stents and discharged respectively on 9 and 10 days postoperatively. The postoperative period was uneventful.

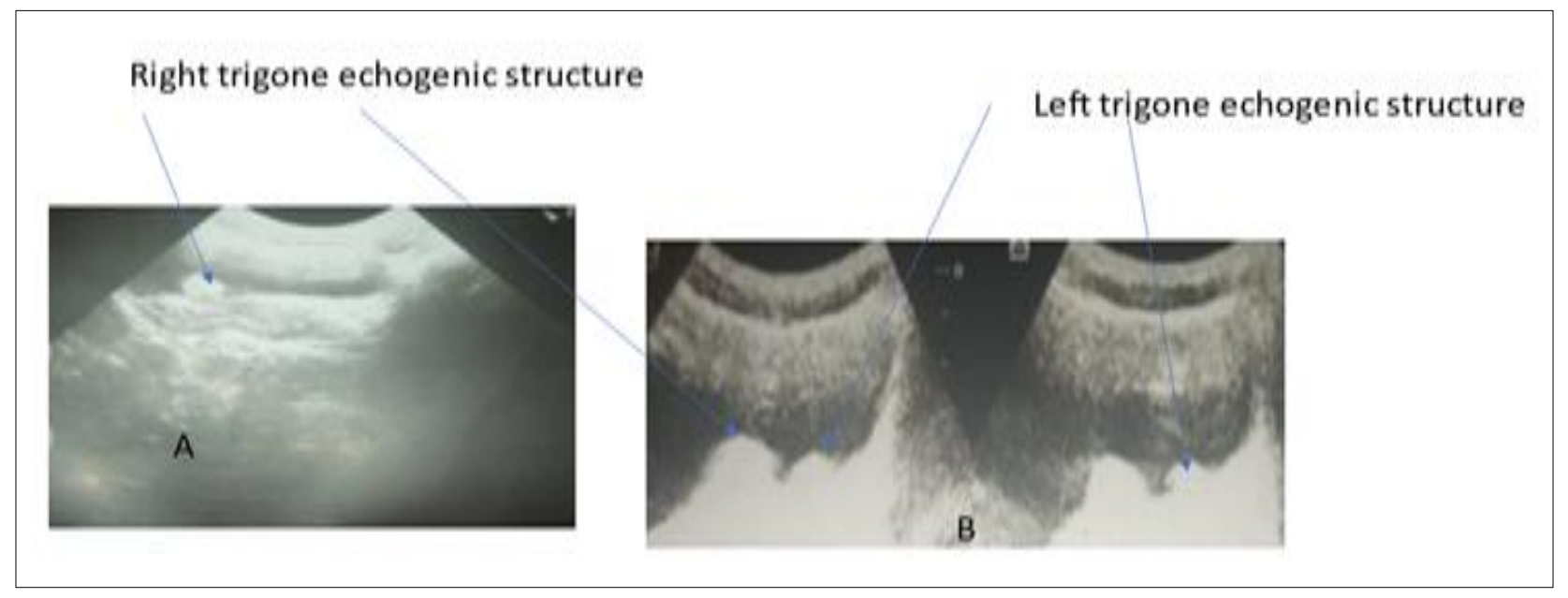

Figure 1 Initial bladder ultrasound scan before MET (A) showing echogenic right trigone structure casting posterior acoustic shadow diagnosed as bladder stone and repeat scan after the MET (B) showing bilateral echogenic structure at the trigone reported as bilateral ureterocoele with stones 


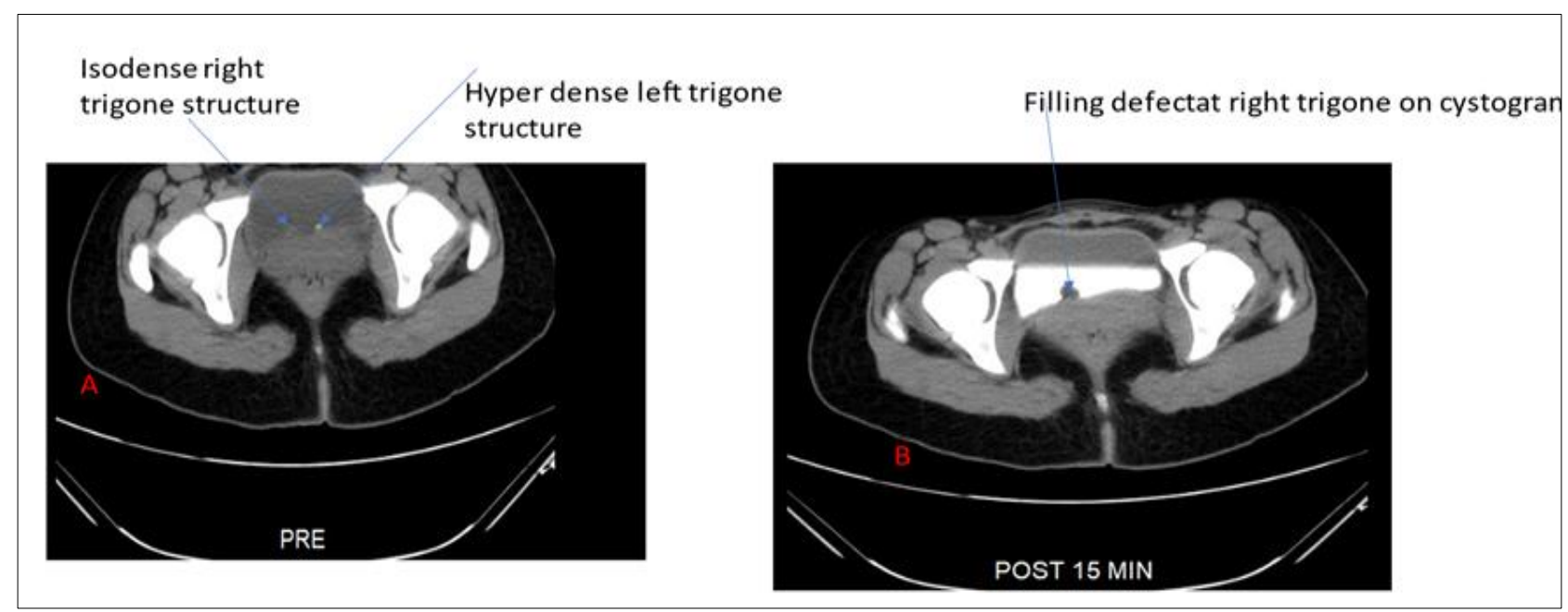

Figure 2 Non- contrast pelvic Computerized Tomography Scan showing isodense (right) and hyperdense (left) areas on pre contrast image (A) and filling defect in the right trigone on cystogram (B) consistent with right ureterocoele stone and left ureteral meatus stone of the trigone. It was reported by the radiologist as right ureterocoele stone and bladder stone

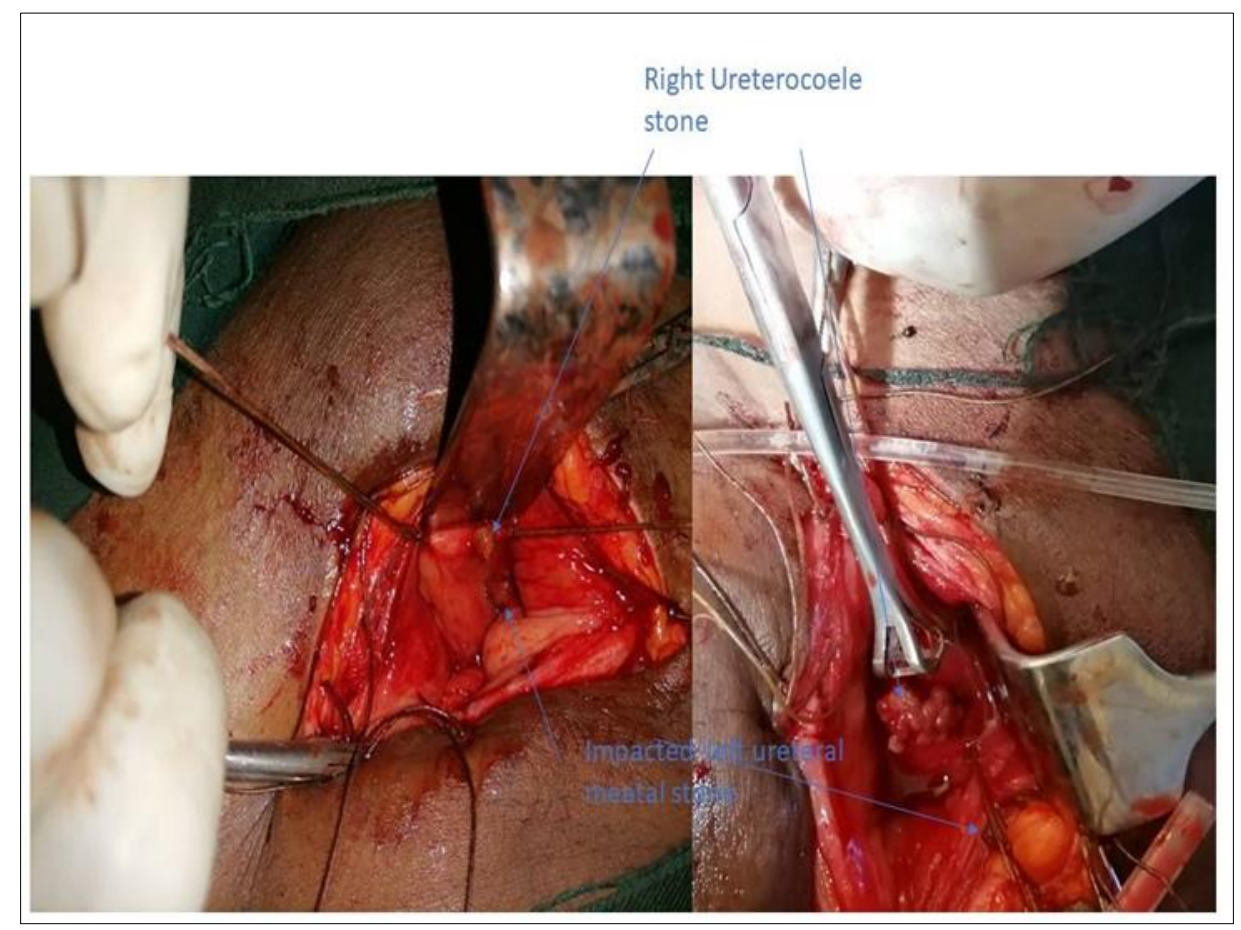

Figure 3 Intraoperative pictures of the right ureterocoele stone and impacted left ureteral meatus stone

\section{Discussion}

A ureterocoele is a cystic dilatation of the intravesical ureter [1]. It is common in Caucasians with an incidence of $1 / 500$ to $1 / 4000$ [2]. It is rare in African and Asians [3]. It occurs more in females 4-7 times than in males [4]. Single system ureterocoele occurs more in adults than children [3]. The most important explanation of the development of ureterocoele is an incomplete dissolution of the Chwalla membrane [8]. Stone formation in a single system is 4-39\% of the cases [6]. It presents in an adult with recurrent abdominal pain which may be due to obstruction, stone formation and infection $[6,12]$. Our patient is an adult and female which is in agreement with what was reported in the previous studies that single system ureterocoeles are common in adults and females $[3,11]$.Our patient presented with recurrent abdominal pain and infection which is consistent with the previous reports [6,7]. The classical cases can be diagnosed by abdominal ultrasound and confirmed by CT urogram. But they may be subjected to observer variability more especially the ultrasound. The diagnostic dilemma experienced was that the stone in the ureterocoele was reportedly 
diagnosed as bladder stone (figure 1) which was radiolucent on the plain abdominal x-ray. The suspicion of meatal stenosis led to commencement of MET which led to the aggravation of the symptoms and withdrawal of the treatment. However, this treatment led to downward migration of another stone in the left ureter. The two stones were demonstrated as echogenic structures at the trigone and diagnosed as bilateral ureterocoeles stones (figure 1B). The CT urogram identified the two echogenic structures but was reported as right ureterocoele stone and bladder stone. The accurate diagnosis was only possible intraoperatively as reported by previous studies $[6,7,12]$. The characteristic findings like a cyst in cyst appearance or cobra head deformity was absent in the index case on ultrasound and CTU probably due to small size of the ureterocoele. This contributed to the diagnostic dilemma.

The phenomenon of the aggravation of the pain with tamsulosin, though possible, was not reported before this due to obstruction of the peristalsis by the blind ureterocoele, huge stone measuring $2.5 \mathrm{x} 3 \mathrm{~cm}$ on the right and impacted left meatus stone of $1.2 \times 1 \mathrm{~cm}$. Therefore, before commencement of MET, obstruction and structural anomaly must be excluded. Ureterocoele can be divided based on the renal unit or location and configuration of the distal ureter. Based on the renal unit it can be a single or duplex system [1]. Based on the location of ureteral meatus, it can be intravesical (orthotopic) or extravesical or (ectopic) [1]. Stephen sub-classifies the orifice into sphincteric, stenotic, spincterostenotic, obstructed, and blind [9]. Our patient had a single system, orthotopic, blind ureterocoele. But due to the absence of the hydronephrosis it could also be stenotic but we were not able to see an opening because of absence of magnification. We offered open deroofing of the ureterocoele and retrieval of the stones bilaterally which was reported to be a standard and effective treatment in the literature $[3,11,12]$. However, endoscopic treatment is an option and feasible. This was not feasible in the facility where we operated. Lesson learned from this case is that, MET should only be tried when the stone is small, not impacted and in the absence of anatomical anomalies such as ureterocoele.

\section{Conclusion}

Medical expulsive therapy may be associated with symptomatic aggravation in blind orthotopic ureterocoele and sizeable impacted ureteral meatus stone. There may be conflicting imaging findings but the standard diagnostic imaging modality is CTU. The accurate diagnosis may be made intraoperatively. Deroofing of the ureterocoele and stone retrieval endoscopically or by open approach is associated with a good outcome.

\section{Compliance with ethical standards}

\section{Acknowledgments}

We acknowledge all the staff of IMAN Hospital Sokoto, Nigeria for their effort during the management and compilation of the case report.

\section{Disclosure of conflict of interest}

No conflict of interest to declare by any of the authors of this case report.

\section{Statement of Ethical approval}

The case report was approved by Health Research and Ethical Committee of IMAN Hospital Runjin Sambo, Nigeria.

\section{Statement of Informed consent}

The consent of the case report including use of pictures was obtained from the patient and her husband.

\section{References}

[1] Peters CA, Mendelsohn C. Ectopic Ureter, Ureterocele, and Ureteral Anomalies Classification and Anatomic Description. General Patterns. In: Wein AJ, Partin AW, Peters CA, editors). Campbell -Walsh's Urology. 11th ed. Philadelphia: Elsevier Saunders. 2016; 3075-3095.

[2] Villanueva CA. Open vs robotic infant ureteroureterostomy. J Paediatr Urol. 2019; 15(4): 390. e1-390.e4.

[3] Muhammed A, Ahmad B, Garba K, Hussaini M, Hyacinth M. Ureterocele in adults: Management of patients in Zaria, Nigeria. Arch Int Surg. 2012; 2(1): 24.

[4] Bhanu Mariyappa 1, Andrew Barker, Naeem Samnakay JK. Management of duplex- system ureterocele. J Paediatr Child Heal. 2014; 50(2): 96-9. 
[5] Stunnel H, Barrett S, Campbell N, Colhoun E, Torreggiani WC. Prolapsed bilateral ureterocele leading to intermittent outflow obstruction. JBR-BTR. 2010; 93(6): 312-3.

[6] Shamsa A, Asadpour AA, Abolbashari M HM. Bilateral simple orthotopic ureteroceles with bilateral stones in adult: A case report and review of literature. Urol J. 2010; 7(3): 209-11.

[7] Kumar Gaurav Mishra, Anshul Garg, Sudish Kumar, Pawan umar Bharti KG. Right-sided ureterocele presented with multiple calculi: A rare case report. J Nephrol Urol Res. 2017; 5: 1-3.

[8] Stephen FD, Smith ED, Hutson JM. Congenital anomalies of the kidney, urinary and genital tracts. Informa Health Care. 2002; 222-5.

[9] Timucin S, Hakan A, Ors B. Late Complication of Duplex System Ureterocele; Acute Urinary Retention, Stone Formation and Renal Atrophy. Int Arch Urol Complic. 2015; 1: 2-4.

[10] Ogwuche EI, Ojo Ba EM. Stone Cobra: "Adult"' left single system ureterocele with 139 calculi- case report and review of the literature. Arch Urol Res. 4(1): 040-042.

[11] Ari P Bernstein, BA Michael Schulster, Brian Chao MMVS. Bilateral open ureterocele with concomitant bladder calculi in an adult. J Endourol Case Reports. 2020; 6(3): 106.

[12] Croitoru S, Gross M, Barmeir E. Duplicated ectopic ureter with vaginal insertion: 3D CT urography with IV and percutaneous contrast administration. Am J Roentgenol. 2007; . 200: 189(5): W272-4. 